Original Research Article

\title{
Current Health Service Experience as a Predictor of Patient Satisfaction: Evidence from Turkey
}

\author{
${ }^{1}$ Evren AYRANCI and ${ }^{2}$ Nazmiye ATALAY \\ ${ }^{1}$ Department of Business Administration, Faculty of Economics and Administrative Sciences, \\ Istanbul Kultur University, Istanbul, 34158, Turkey \\ ${ }^{2}$ Department of Management, Istanbul AREL University, Institute of Social Sciences, Istanbul, 34528, Turkey
}

Article history

Received: 10-07-2019

Revised: $15-07-2019$

Accepted: 19-07-2019

Corresponding Author: Evren AYRANCI

Faculty of Economics and Administrative Sciences,

Department of Business

Administration, Istanbul Kultur

University, Istanbul, 34158

Turkey

Tel: +90 5324054094

Fax: +902128556097

Email: e.ayranci@iku.edu.tr

\begin{abstract}
This study scrutinizes effects of current health service experience on patient satisfaction. The investigation included 337 participants, who were actively receiving health services from the largest public hospitals' clinics in Turkey. An examination of the experience's and satisfaction's statistical structures is made; therefore, exploratory factor and reliability analyses were applied. A structural equation modeling was used consecutively to determine the experience's effects on satisfaction integratively. Instrument combinations were used for both ends distinctively for a peripheral approach. The tripartite experience is fully effective on satisfaction, which encompasses five elements. The experience has the strongest connection with satisfaction via Hospital Context's Physical Aspects (HCPA) $\left(\mathrm{R}^{2}=0.88\right)$ and Attitude Of Doctor (AOD) $\left(\mathrm{R}^{2}=\right.$ 0.70). The weakest connection involves satisfaction from Attitudes Of Administrative Personnel (AOAP) $\left(\mathrm{R}^{2}=0.24\right)$. Two experience factors, initial contact (IC) and Awareness (AW), pose the greatest positive effects on HCPA (IC-HCPA, $\gamma$ : 1.97, S.E.: 0.0058, $t$ : 338.79; AW-HCPA, $\gamma: 0.96$, S.E.: 0.0054, $t:$ 179.07) and AOD (IC-AOD, $\gamma: 2.15$, S.E.: 0.0057, $t$ : 378.32; AW-AOD, $\gamma: 1.08$, S.E.: 0.0064, $t$ : 167.92). Most of the effects is positive at factor level generally, with two exceptions: the effect of IC on $\operatorname{AOAP}(\gamma:-0.32$, S.E.: $0.0049, t:-65.73)$ and that of AW on AOAP $(\gamma:-$ 0.26 , S.E.: $0.0073, t:-35.88)$. Current health service experience is fully and supportively effective on patient satisfaction broadly, but the nature of this effect varies in terms of intensity and direction at factor level.
\end{abstract}

Keywords: Patient Satisfaction, Health Service, Hospital, Turkey

\section{Introduction}

The scope of the health sector is vast, but as the primary emphasis is on patients, the issue of their satisfaction is vital. Hospital members, as expected, are key players in building patient satisfaction through their interactions with patients during health services. The foremost members are doctors, because they are the first agents of encounter for a professional medical solution (Kee et al., 2018).

With a normative approach for patient-doctor relationships (Gordon and Edwards, 1997), it is concluded that doctors should approach patients in a trust-building, warm, delicate and encouraging manner; try to use empathy while understanding patients; use a simple phraseology to express the situation and possible outcomes; avoid being dominant during dialogues and provide clear treatment options to patients. Some components of this normative approach are further evidenced in the literature. Stewart et al. (1999) proved that a patient's mention of the doctor's manners and expressions is an actual determinant of patient satisfaction. Williams (1994) showed that patients are usually unaware of treatment options and quality and hence, their satisfaction assessments are not true. This situation necessitates doctors to provide possible cure options in plain language and inform patients consistently. According to (Roter et al., 1997), doctors are very effective in encouraging patient satisfaction as long as they avoid using medical jargon heavily and show empathy.

In addition to doctors, patients also spend time with nurses. This fact places emphasis on nurses' 
communication and empathy skills, behaviors and selfawareness toward patients as these could reduce patients' worries (Kangas et al., 1999; Findik et al., 2010). Patient satisfaction is also dependent upon nurses' care for their own duties; satisfaction rises when nurses pay strict attention to patient surveillance, show the utmost effort to help patients in their treatment processes, prepare patients for treatment processes regard fully and get patients ready and aware for their care after discharge (Vahey et al., 2004).

The emphasis on doctors and nurses is a natural outcome; nevertheless, it should be remembered that there are other hospital staff who directly interact with patients when necessary. These include laboratory personnel, patient record and help desk clerks and food and cleaning services employees. Absolute outcomes are that their interactions with patients require empathy and good communication skills (Kırmız1, 2010), the speed of dealing with patient problems is essential (Boulding et al., 2011) and they should be deeply committed to the teamwork of doctors and nurses to encourage patient satisfaction (Meterko et al., 2004).

Moreover, the literature reports a general approach to consider hospital members together rather than uncoupling doctors, nurses and others. Accordingly, the main frame is built on trust and privacy. The patient's need for oriented or even customized care brings forth the issue of trust. To build and maintain trust, all active members should convince patients that they are deeply cared for (Entwistle and Quick, 2006), the hospital context is safe (Rhodes et al., 2016) and enough and reasonable information is provided (Tang and Newcomb, 1998). Trust enriches both patient satisfaction and harmony in the treatment process (Isik and Tulunoglu, 2007). An amusing finding about privacy is that it is usually considered otherwise - in the form of privacy violations. Therefore, patient perceptions about their privacy violations are reported to end with conflicts, dissatisfaction and deviations from performing the requirements of the treatment process (Silvestro, 2005).

A final fact to consider is the hospital context in terms of operation conduct and physical features. Extensively detailed paperwork and bureaucratic operations taking too long could easily deteriorate patient satisfaction. These negative side-effects of bureaucracy result in time losses and therefore, satisfaction declines (Fitzpatrick, 1991). In dealing with time spent in hospitals, the literature has discovered that this is divided into three parts: time losses due to waiting to start the health service (Worthington, 1987) or surgery (Weiss, 1990), losses that stem from the time frame between getting an appointment and the appointment's start time (Harper and Gamlin, 2003) and time spent to prepare and process necessary incoming and outgoing patient records (O'Leary et al., 2006; Khanna et al., 2016).

Physical features refer to the hospital's accessibility, hygiene, convenience and adequacy of equipment. There is enough proof that the overall physical factors (Butler et al., 1996) and distinctive factors, such as accessibility (availability of a specific health service) (Turner and Pol, 1995; Ho et al., 1998) and convenience (the existence of appropriate therapeutic measures) (Tucker, 2002), have an effect on patient satisfaction.

Considering all these, this study has the purpose of finding out how patient satisfaction is affected by patients' experience with their current health service.

\section{Materials and Methods}

It is expected that an effect will be unearthed, much like the findings in the literature; therefore, the following closed-form research model is proposed in Fig. 1. The model is yet to be expanded with details after the statistical structures are scrutinized.

The largest general public hospitals in Turkey were considered for many reasons. Hospitals are the dominant health institutions in Turkey (Okursoy, 2010) and this reality necessitates a selection among different hospital types. The selection was made among general hospitals, as the interest is on pinpointing overall patient satisfaction instead of satisfaction with special hospitals or specific treatments. The last step was to choose between public or private hospitals. It was assumed that public hospitals would provide a clearer picture of patient satisfaction and experience, owing to their full potentiality in patient care without a close consideration of the costs and revenues. The application of these reasons resulted in five hospitals; therefore, patients who were actively receiving health services from these hospitals' clinics were within the scope. The accessible hospital records indicated a total of 29,661 patients and the sample size was calculated to be 380 with a $5 \%$ margin of error and $95 \%$ confidence level (Raosoft, 2004). However, there were only 337 patients who agreed to participate in the research.

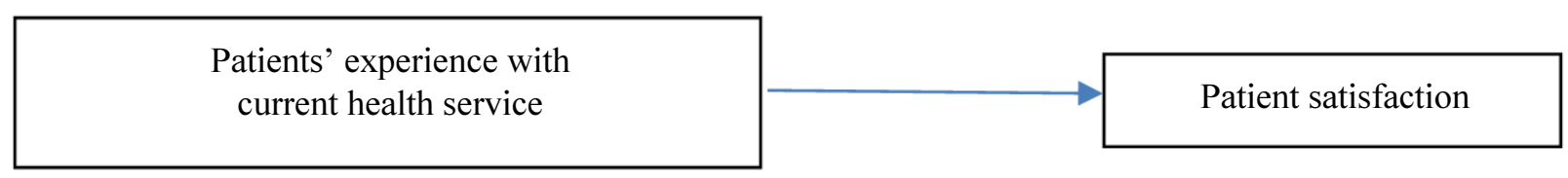

Fig. 1: Closed-form research model 
Data were collected via questionnaires, which comprised two parts. The first part dealt with the current health service experience, whereas the second part scrutinized patient satisfaction. To arrive at a general scope regarding patient satisfaction, many items and instruments were combined. These mostly included Turkish contextspecific ones developed by (Akbas, 2014; Tüfekçi and Asığbulmuş 2016; Atilla, 2012; Ipek, 2010; Karaalp, 2014; Kuzhan, 2009) along with the EUROPEP (Grol and Wensing, 2000) scale. Health service experience does not have any specific instrument; therefore, the related research (Worthington, 1987; Fitzpatrick, 1991; Turner and Pol, 1995; Butler et al., 1996; Roter et al., 1997; Ho et al., 1998; Tang and Newcomb, 1998; Kangas et al., 1999; Tucker, 2002; Harper and Gamlin, 2003; Meterko et al., 2004; Vahey et al., 2004; Silvestro, 2005; Entwistle and Quick, 2006; Isik and Tulunoglu, 2007; Findik et al., 2010; Kırmızı, 2010; Boulding et al., 2011; Rhodes et al., 2016) was scanned to extract necessary criteria.

\section{Results}

\section{Statistical Structure of Patient Satisfaction}

The use of multiple instruments necessitated a test of their combinations to figure out how patient satisfaction is shaped; therefore, an exploratory factor analysis was performed using a principal components analysis, varimax rotation and suppression of factor loads less than $|0.5|$. The results in Table 1 indicate a five-factor patient satisfaction structure with an overall $65.9 \%$ of variance explained. Table 1 also shows that all factors, as well as all items, have good reliability levels.
The results in Table 1 show that patient satisfaction abides by the majority of the literature; it is composed of the hospital's physical and psycho-social aspects, as well as the attitudes of hospital members, including doctors, nurses, other health personnel and administrative personnel.

\section{Statistical Structure of Current Health Service Experience}

The current health service experience includes nine items that were extracted after investigating the related studies; therefore, an exploratory factor analysis was conducted, using the same settings as those used for patient satisfaction. The related results, along with the reliability analyses outcomes, are displayed in Table 2 . The total variance explained is $69.016 \%$.

According to Table 2, patients stated that their current experience has three factors: speed and convenience of the initial contact with the hospital, nurses and doctors; overall speed of the health service and their consciousness regarding their choices and confidence in their treatment.

\section{Effects on Patient Satisfaction}

The ultimate aim mentioned is to find out whether and how patient satisfaction is affected by the patient's current health service experience. Due to the nature of the data, structural equation modeling was performed. Fig. 2 exhibits the research model in an open form - with the emerged statistical structures taken into consideration. For a cursory glance, Fig. 2 also includes the t-values, indicating that all relationships are statistically significant at $5 \%$.

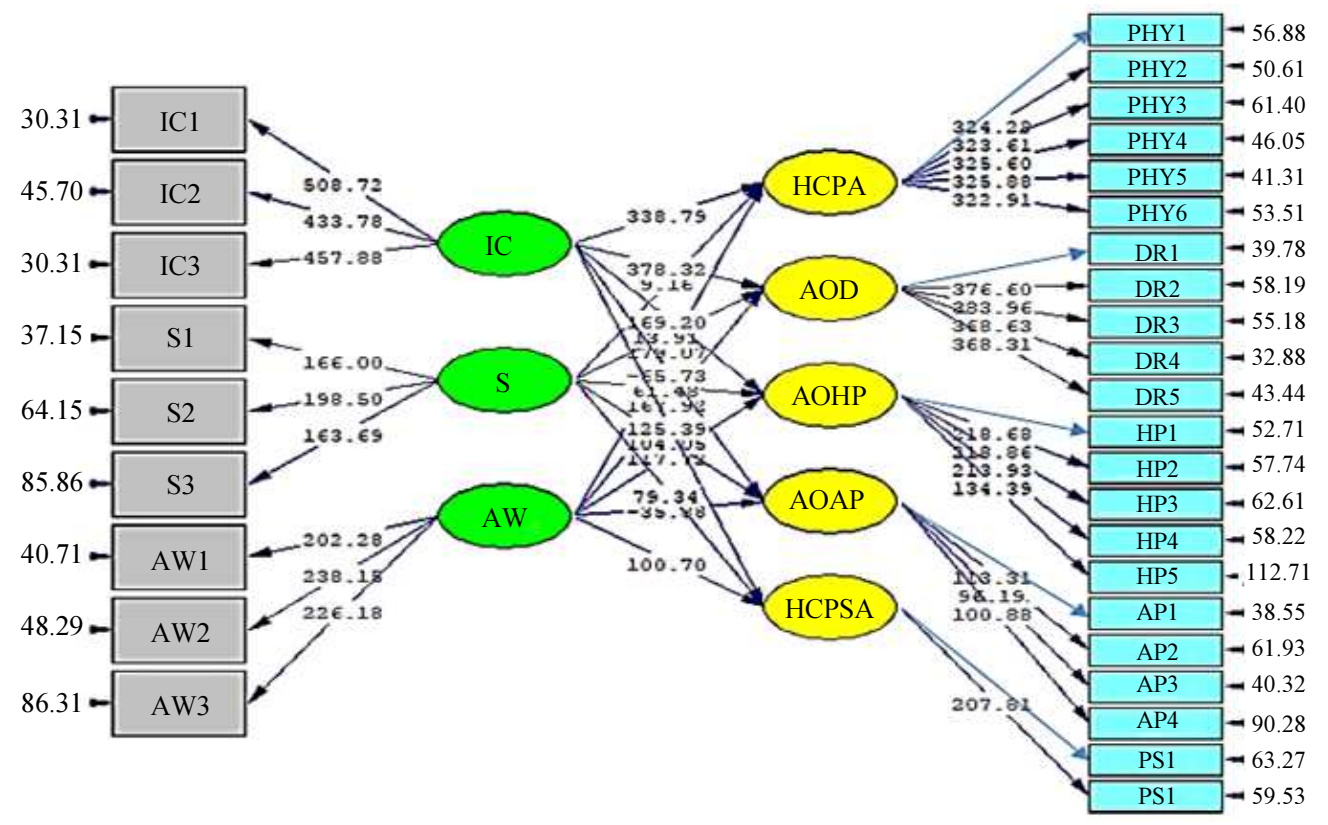

Fig. 2: Detailed research model with t-values (See Tables 1 and 2 for abbreviations) 
Table 1: Results of exploratory factor and reliability analyses of patient satisfaction KMO Value: 0.897 (Bartlett's test value is statistically significant)

\begin{tabular}{|c|c|c|c|c|c|}
\hline & $\begin{array}{l}\text { Hospital Context: } \\
\text { Physical Aspects } \\
\text { (HCPA) }\end{array}$ & $\begin{array}{l}\text { Attitude } \\
\text { of Doctor } \\
\text { (AOD) }\end{array}$ & $\begin{array}{l}\text { Attitude of } \\
\text { Health Personnel } \\
\text { (AOHP) }\end{array}$ & $\begin{array}{l}\text { Attitude of } \\
\text { Administrative } \\
\text { Personnel (AOAP) }\end{array}$ & $\begin{array}{l}\text { Hospital Context: } \\
\text { Psycho-Social } \\
\text { Aspects (HCPSA) }\end{array}$ \\
\hline Variance Explained (\%) & 19.021 & 16.857 & 12.348 & 10.734 & 6.940 \\
\hline Cronbach's Alpha Value & 0.906 & 0.917 & 0.765 & 0.734 & 0.639 \\
\hline Overall Cronbach's Alpha Value & & & 0.878 & & \\
\hline $\begin{array}{l}\text { Service departments and polyclinics of } \\
\text { the hospital were clean. (PHY4) }\end{array}$ & 0.850 & & & & \\
\hline $\begin{array}{l}\text { It was easy to access departments in the } \\
\text { hospital building. (PHY2) }\end{array}$ & 0.798 & & & & \\
\hline Toilets in the hospital were clean. (PHY5) & 0.769 & & & & \\
\hline $\begin{array}{l}\text { Guidance plates in the hospital were readable } \\
\text { and understandable. (PHY1) }\end{array}$ & 0.719 & & & & \\
\hline Car parking facilities were adequate. (PHY3) & 0.698 & & & & \\
\hline $\begin{array}{l}\text { There was enough heating and lighting in the } \\
\text { departments I was in. (PHY6) }\end{array}$ & 0.697 & & & & \\
\hline $\begin{array}{l}\text { My doctor spared enough time and informed } \\
\text { me well. (DR3) }\end{array}$ & & 0.866 & & & \\
\hline $\begin{array}{l}\text { My doctor gave me the chance to ask many } \\
\text { questions regarding my disorder. (DR4) }\end{array}$ & & 0.835 & & & \\
\hline $\begin{array}{l}\text { My doctor called me for an initial medical } \\
\text { examination on time. (DR } 1 \text { ) }\end{array}$ & & 0.829 & & & \\
\hline $\begin{array}{l}\text { My doctor gave me recommendations about } \\
\text { what to do after treatment. (DR2) }\end{array}$ & & 0.690 & & & \\
\hline $\begin{array}{l}\text { My doctor used a very understandable style of } \\
\text { speaking. (DR5) }\end{array}$ & & 0.669 & & & \\
\hline $\begin{array}{l}\text { Health technicians were courteous and caring } \\
\text { enough. (HP4) }\end{array}$ & & & 0.773 & & \\
\hline $\begin{array}{l}\text { Health clerks were courteous and caring } \\
\text { enough. (HP3) }\end{array}$ & & & 0.763 & & \\
\hline $\begin{array}{l}\text { Nurses and other health staff were affirmative } \\
\text { in terms of their personal care, clothing and } \\
\text { approach. (HP1) }\end{array}$ & & & 0.680 & & \\
\hline Nurses were courteous and caring enough. (HP2) & & & 0.651 & & \\
\hline $\begin{array}{l}\text { I could clearly understand nurses' and other health } \\
\text { staffs'speech. (HP5) }\end{array}$ & & & 0.589 & & \\
\hline $\begin{array}{l}\text { Administrative personnel were sensitive and caring } \\
\text { toward my problems in general. (AP1) }\end{array}$ & & & & 0.809 & \\
\hline $\begin{array}{l}\text { Security guards were caring and guided me } \\
\text { well. (AP4) }\end{array}$ & & & & 0.796 & \\
\hline $\begin{array}{l}\text { Information clerks were caring and guided } \\
\text { me well. (AP3) }\end{array}$ & & & & 0.750 & \\
\hline Administrative personnel were in harmony. (AP2) & & & & 0.586 & \\
\hline Privacy was considered while & & & & & \\
\hline I was being examined. (PS1) & & & & & 0.793 \\
\hline I felt safe in this hospital. (PS2) & & & & & 0.765 \\
\hline
\end{tabular}

Table 2: Results of exploratory factor and reliability analyses of current health service experience

KMO Value: 0.699 (Bartlett's test value is statistically significant).

\begin{tabular}{lll} 
& Speed (S) & \multicolumn{1}{c}{ Awareness (AW) } \\
\hline Variance Explained (\%) & Initial Contact (IC) & 22.776 \\
Cronbach's Alpha Value & 24.611 & 0.762 \\
Overall Cronbach's Alpha Value & 0.825 & 0.708 \\
My initial contact with the hospital & 0.909 & 0.711 \\
was quick and easy. (IC1) & & 0.820 \\
I could easily contact nurses in the beginning. (IC2) & 0.785 & 0.870 \\
I could easily contact the doctor in & \\
the beginning. (IC3) & \\
The time frame between the appointment & \\
and the initial medical examination was short. (S2) & \\
I did not wait long during my treatment process. (S1) & \\
Paperwork was quickly finished. (S3) & \\
I deliberately chose this hospital. (AW1) & \\
I deliberately chose this (these) clinic(s). (AW3) & \\
I am confident that I am being taken care of well. (AW2) & \\
\hline
\end{tabular}


Table 3: Fit indices of the research model

\begin{tabular}{|c|c|c|c|}
\hline Fit index & Value & Proposed Limits & Result \\
\hline $\begin{array}{l}\text { Root Mean Square Error } \\
\text { of Approximation (RMSEA) }\end{array}$ & 0.081 & $\begin{array}{l}\text { Good fit: RMSEA }<0.05 \\
\text { Acceptable fit: } 0.05 \leq \text { RMSEA } \leq 0.1\end{array}$ & Acceptable fit \\
\hline Goodness of Fit Index (GFI) & 0.96 & $\begin{array}{l}\text { Good fit: } 0.95 \leq \mathrm{GFI} \leq 1.00 \\
\text { Acceptable fit: } 0.9<\mathrm{GFI}<0.95\end{array}$ & Good fit \\
\hline Adjusted Goodness of Fit Index (AGFI) & 0.96 & $\begin{array}{l}\text { Good fit: } 0.95 \leq \mathrm{AGFI} \leq 1.00 \\
\text { Acceptable fit: } 0.9<\mathrm{AGFI}<0.95\end{array}$ & Good fit \\
\hline Comparative Fit Index (CFI) & 1.00 & $0.90 \leq \mathrm{CFI}$ & Good fit \\
\hline Standardized Root Mean Square Residual (SRMR) & 0.071 & $\mathrm{SRMR}<0.05$ & Unacceptable fit \\
\hline
\end{tabular}

Table 4: Measurement equations for the dependent variables

\begin{tabular}{|c|c|}
\hline \multicolumn{2}{|c|}{ Hospital Context: Physical Aspects (HCPA) } \\
\hline PHY $1=1.00 *$ HCPA, Errorvar. $=4.69, \mathrm{R}^{2}=0.54$ & PHY $4=1.16 *$ HCPA, Errorvar. $=3.76, \mathrm{R}^{2}=0.66$ \\
\hline$(0.082)$ & $(0.0036) \quad(0.082)$ \\
\hline 56.88 & 325.60 \\
\hline PHY2 $=1.03 *$ HCPA, Errorvar. $=4.09, \mathrm{R}^{2}=0.59$ & PHY5 $=1.24 * H C P A$, Errorvar. $=3.41, \mathrm{R}^{2}=0.71$ \\
\hline$(0.0032) \quad(0.081)$ & $\begin{array}{ll}(0.0038) & (0.082)\end{array}$ \\
\hline $324.28 \quad 50.61$ & 325.88 \\
\hline PHY3 $=1.06 *$ HCPA, Errorvar. $=4.97, \mathrm{R}^{2}=0.55$ & PHY6 $=1.14 * \mathrm{HCPA}$, Errorvar. $=4.37, \mathrm{R}^{2}=0.62$ \\
\hline$(0.0033) \quad(0.081)$ & $\begin{array}{ll}(0.0035) & (0.082)\end{array}$ \\
\hline 323.61 & 322.91 \\
\hline \multicolumn{2}{|c|}{ Attitude of Doctor (AOD) } \\
\hline$\overline{\mathrm{DR}} 1=1.00 * \mathrm{AOD}$, Errorvar. $=3.38, \mathrm{R}^{2}=0.71$ & $\mathrm{DR} 4=1.06 * \mathrm{AOD}$, Errorvar. $=2.76, \mathrm{R}^{2}=0.77$ \\
\hline$(0.085)$ & $(0.0029) \quad(0.084)$ \\
\hline 39.78 & $368.63 \quad 32.88$ \\
\hline $\mathrm{DR} 2=0.96 * \mathrm{AOD}$, Errorvar. $=4.80, \mathrm{R}^{2}=0.61$ & $\mathrm{DR} 5=1.00 * \mathrm{AOD}$, Errorvar. $=3.58, \mathrm{R}^{2}=0.70$ \\
\hline$(0.0025) \quad(0.083)$ & $(0.0027) \quad(0.083)$ \\
\hline $376.60 \quad 58.19$ & 368.31 \\
\hline \multirow{3}{*}{\multicolumn{2}{|c|}{$\begin{array}{c}\text { DR3 }=1.00 * \text { AOD, Errorvar. }=4.58, R^{2}=0.64 \\
\begin{array}{cc}(0.0026) & (0.083) \\
383.96 & 55.18\end{array}\end{array}$}} \\
\hline & \\
\hline $\begin{array}{ll}383.96 & 55.18 \\
\end{array}$ & \\
\hline \multicolumn{2}{|c|}{ Attitude of Health Personnel (AOHP) } \\
\hline $\mathrm{HP} 1=1.00 * \mathrm{AOHP}$, Errorvar. $=4.56, \mathrm{R}^{2}=0.53$ & $\mathrm{HP} 4=0.87 * \mathrm{AOHP}$, Errorvar. $=4.79, \mathrm{R}^{2}=0.45$ \\
\hline$(0.087)$ & $(0.0041) \quad(0.082)$ \\
\hline 52.71 & $213.93 \quad 58.22$ \\
\hline $\mathrm{HP} 2=0.96^{*} \mathrm{AOHP}$, Errorvar. $=4.89, \mathrm{R}^{2}=0.50$ & $\mathrm{HP} 5=0.40 * \mathrm{AOHP}$, Errorvar. $=8.79, \mathrm{R}^{2}=0.38$ \\
\hline$(0.0044)$ & $(0.0030) \quad(0.078)$ \\
\hline $218.68 \quad 57.74$ & 134.39 \\
\hline \multirow{2}{*}{\multicolumn{2}{|c|}{$\mathrm{HP} 3=0.95 * \mathrm{AOHP}$, Errorvar. $=5.26, \mathrm{R}^{2}=0.47$}} \\
\hline$(0.0044)$ & \\
\hline 218.86 & \\
\hline \multicolumn{2}{|c|}{ Attitude of Administrative Personnel (AOAP) } \\
\hline $\mathrm{AP} 1=1.00 * \mathrm{AOAP}$, Errorvar. $=3.96, \mathrm{R}^{2}=0.56$ & $\mathrm{AP} 3=0.98 * \mathrm{AOAP}$, Errorvar. $=3.99, \mathrm{R}^{2}=0.55$ \\
\hline$(0.10)$ & $(0.010) \quad(0.099)$ \\
\hline 38.55 & $96.19 \quad 40.32$ \\
\hline $\mathrm{AP} 2=0.83 * \mathrm{AOAP}$, Errorvar $=5.47, \mathrm{R}^{2}=0.39$ & $\mathrm{AP} 4=0.64 * \mathrm{AOAP}$, Errorvar. $=7.48, \mathrm{R}^{2}=0.22$ \\
\hline$(0.0073) \quad(0.088)$ & $(0.0063) \quad(0.083)$ \\
\hline $113.31 \quad 61.93$ & $\begin{array}{ll}100.88 & 90.28 \\
\end{array}$ \\
\hline \multicolumn{2}{|c|}{ Hospital Context: Psycho-Social Aspects (HCPSA) } \\
\hline PS1 $=1.00 *$ HCPSA, Errorvar. $=6.11, \mathrm{R}^{2}=0.44$ & PS2 $=1.11 *$ HCPSA, Errorvar. $=5.96, \mathrm{R}^{2}=0.50$ \\
\hline$(0.097)$ & $(0.0054) \quad(0.10)$ \\
\hline 63.27 & $207.81 \quad 59.53$ \\
\hline
\end{tabular}

Table 3 presents the model's fit indices and the overall model appears to be realistic once its fit indices are compared to the limits proposed in the literature (Diamantopoulos and Siguaw, 2000; Schermelleh-Engel et al., 2003).
An in-depth investigation is the next step and thus, measurement equations are checked. The first investigation, denoted in Table 4 , belongs to the dependent variables that form the patient satisfaction.

Table 4 reveals noteworthy findings. An overall look shows that the statistical structures emerged are preserved. 
It is also striking that many items have moderate or strong relationships with their respective factors and that each item contributes to its factor positively.

There are, however, some distinctions. To start with, the most powerful connections overall are between attitude of doctor and its items, followed by those between physical aspects of hospital context and its related items. On the other hand, the weakest harmony in general could be observed when relationships between attitude of administrative personnel and the related items are in question. A detailed check on the aforesaid contributions points out a resembling outcome to the case with connection strengths-the biggest contributions are made by the items of attitude of doctor and physical and psycho-social aspects of hospital context to their respective factors.

The following Table 5, presents those measurement equations for the independent variables this time. These variables belong to the components of current health service experience.

Table 5 implies a similarity to the situation of the dependent variables given in Table 4. There are moderate and strong relationships, positive contributions and the conservation of the original structure. A distinct feature of the independent variables is that each item is able to encourage its respective factor much powerfully in comparison to the dependent variables.

The statistical validity of the model along with appropriate measurement equations necessitated the investigation of the research hypothesis; therefore, structural equations between patient satisfaction and the current health service experience are reported in Table 6 .

The results presented in Table 6 give rise to the conclusion that patient satisfaction is affected by the patient's current health service experience. The table, moreover, reveals noteworthy outcomes. The foremost outcome is that the patients' experience had the strongest connection to their satisfaction with physical aspects of the hospital (HCPA) $\left(\mathrm{R}^{2}: 0.88\right)$, followed by their satisfaction with doctors' attitudes (AOD) $\left(\mathrm{R}^{2}: 0.70\right)$. With a sharp decline in the coefficient of determination, the experience and satisfaction with Hospital Context's Psycho-Social Aspects (HCPSA) relationship was third $\left(\mathrm{R}^{2}: 0.40\right)$ and the experience and satisfaction with health personnel attitude (AOHP) relationship was fourth $\left(\mathrm{R}^{2}\right.$ : 0.32). The loosest connection was between the experience and satisfaction with the Attitudes Of Administrative Personnel (AOAP) $\left(\mathrm{R}^{2}: 0.24\right)$. Therefore, patients considered that their satisfaction was not monolithic in terms of the effect posed by their experience. While satisfaction with the physical hospital context and attitude of doctors were posited to be very closely related to health service experience, the strength of relationship declined profoundly once other satisfaction factors were accounted for. Administrative personnel attitudes, moreover, were not much perceived as a part of the health service experience in comparison to others in order to affect the satisfaction.

All the satisfaction factors were contributed positively by all the experience factors, except for one: satisfaction with the attitudes of administrative personnel.

It is a catch that the initial contact and awareness factors of the experience deteriorated satisfaction with administrative personnel attitudes $(\gamma:-0.32$, S.E.: 0.0049, $t:-65.73$ and $\gamma:-0.26, \quad$ S.E.: $0.0073, \quad t:-35.88$ respectvely), whereas patients' experienced speed of such personnel was a positive contributor $(\gamma: 1.02$, S.E.: $0.0098, t$ : 104.05). One implication is the possibility of administrative personnel's unfavorable behavior during the first contact with hospitals, nurses and doctors.

Table 5: Measurement equations for the independent variables

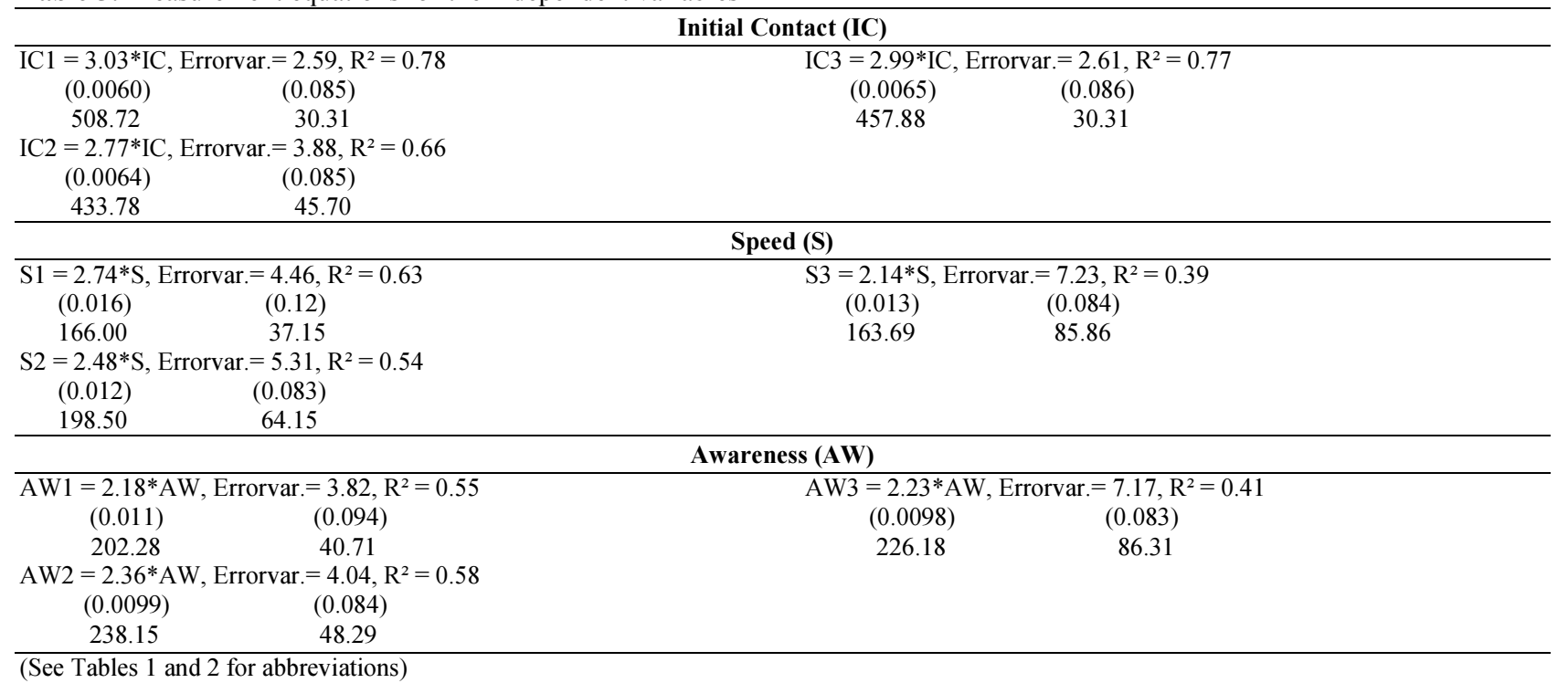




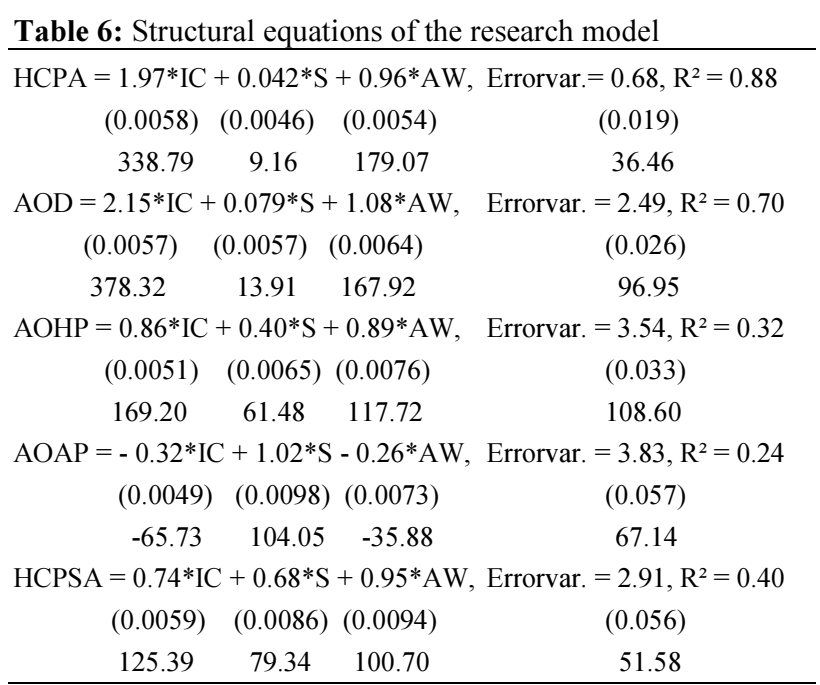

(See Tables 1 and 2 for abbreviations)

Another implication could be the perception of patients that they were misled or not helped enough by the administrative staff during hospital and clinic choices or throughout the hospital environment.

An examination of the coefficient values enabled a comparison among each experience factor in terms of contributing to patient satisfaction. The speed, ease and convenience of the initial contact with hospitals, nurses and doctors had the strongest positive effects on satisfaction with the physical hospital context $(\gamma: 1.97$, S.E.: $0.0058, t: 338.79)$ and attitudes of doctors $(\gamma: 2.15$, S.E.: $0.0057, t: 378.32)$. This outcome suggested that the patients were contented about their doctors and hygiene, accessibility and guidance of the hospital upon their first interaction with the hospital environment.

Awareness factor of the experience acted similarly and enforced satisfaction with physical hospital context profoundly $(\gamma: 0.96$, S.E.: $0.0054, t: 179.07)$ and it further boosted satisfaction with attitudes of doctors $(\gamma$ : 1.08, S.E.: $0.0064, t: 167,92)$. Due to the nature of awareness, it involved deliberate hospital and clinic choices and confidence in treatment. It seemed that this specific nature paid off.

Despite these noteworthy contributions to the mentioned satisfaction factors, the speed component of experience failed to do so. Its weak encouraging effects on satisfaction with physical hospital context $(\gamma: 0.042$, S.E.: $0.0046, t: 9.16)$ and attitudes of doctors $(\gamma: 0.079$, S.E.: $0.0057, t: 13.91)$ implied that the patients did not assign a high priority to the speed of paperwork, treatment and time frame length between appointment and medical examination once their contentment regarding hospitals' physical features and attitudes of doctors were asked.

A look on the rest of the satisfaction factors, namely satisfaction with attitudes of health personnel and psycho-social hospital context, revealed that they were positively and nearly equally affected by the experience's initial contact $(\gamma: 0.86$, S.E.: 0.0051, $t$ : 169.20 and $\gamma: 0.74$, S.E.: $0.0059, t: 125.39$ respectively) and awareness $(\gamma: 0.89$, S.E.: $0.0076, t: 117.72$ and $\gamma$ : 0.95 , S.E.: $0.0094, t: 100.70$ respectively) factors. The other experience factor, speed, was a weaker determinant of satisfaction with attitudes of health personnel $(\gamma: 0.40$, S.E.: 0.0065, $t:$ 61.48) and hospitals' psycho-social context $(\gamma: 0.68$, S.E.: $0.0086, t: 79.34)$. A combination of the previous finding about speed and this current one urged the idea that the patients did not consider the speed to be as influential as the other factors of experience in general when their satisfaction was under the spotlights.

\section{Conclusion and Recommendations}

This study investigated two issues in some of the largest public hospitals in Turkey: how patient satisfaction is shaped and how this satisfaction is affected by the patients' current experience. The results show that patient satisfaction is composed of physical and psycho-social aspects of the hospital context, in addition to the attitudes of doctors, nurses, other health staff and administrative personnel toward patients. The other end, the health service experience, depends on the conditions of the initial contact with hospitals, doctors and nurses; speed of paperwork, treatment process and time between appointment and initial medical examination and patient awareness about the hospital and clinic choices and confidence for an effective treatment.

Patients perceive the physical features of the hospitals and the doctors' attitudes as the foremost satisfaction elements under the influence of their experience. Though other satisfaction elements are also affected by the experience, the intensities of the connections are in poorer condition in comparison. The analysis, moreover, highlights that the experience affects patient satisfaction positively, with only two negative exceptions related to satisfaction with administrative personnel. These exceptions suggest that the administrative personnel could have refrained from providing the expected help, guidance and behaviors to patients.

Patients also report that their first contact with the hospital environment, as well as their sentience and confidence, encourage their satisfaction with their doctors and physical features of hospitals. Nevertheless, they propose that the speed of operations and paperwork in hospital domain is a lesser influential factor over these two satisfaction dimensions.

For the two other satisfaction dimensions, satisfaction with attitudes of health personnel and hospitals' psychosocial context, a very similar picture is present: all the three experience factors boost these dimensions, but the speed is a straggler. 
The ultimate conclusion is that the patients' current health service experience is entirely effective on their satisfaction, but the nature of this effect shows variations at factor level. While all the three experience factors are influencers, speed is only able to pose a weaker effect on the satisfaction overall. The experience's adjuvant effects on the satisfaction are exempted once satisfaction with attitudes of administrative personnel is in question. Attitudes of doctors and physical hospital facilities are the two satisfaction elements that are exposed to the effects of health service experience the most.

All these facts urge some recommendations. This study has an overall look on the mentioned relationship, but it is believed that further useful insights could be reached once a more focused approach is taken. Future studies, for instance, could investigate the relationship using data from specific clinics, types of hospitals, or hospitals from specific regions or even countries. This approach is expected to provide an opportunity to account for any contextual differences in the nature of the relationship and it also enables comparisons. The focused approach could also be longitudinal; and therefore, temporal changes of the relationship could be monitored within many contexts. Another recommendation would be the involvement of other related issues for a greater multifaceted approach. Possible candidates such as cost of treatment, food quality and treatment individualization could be of value to distinguish possible aspects that are not seen as relevant by patients regarding the relationship.

Besides these recommendations for future research, another set of recommendations belongs to practicability. Due to being one of the most powerful determinants, hospitals under question and in general should pay close attention to their doctors' behaviors towards their patients besides checking their professional competencies. While a more patient-friendly physical environment is recommended, non-health care hospital workers should attend to professional communication courses.

\section{Authors' Contributions}

Evren AYRANCI: Organized the study, contributed to the literature review and data collection process, designed the theoretical frame and the research model, preformed the analyzes, commented on the results, made the recommendations.

Nazmiye ATALAY: Performed the literature review and data collection process, contributed to the writing of the paper.

\section{Ethics}

Ethical issues (plagiarism, informed consent, misconduct, data fabrication and/or falsification, double publication and/or submission, redundancy, etc.) have been completely observed by the authors.

\section{References}

Akbas, E., 2014. Patients' contentment in health care services and the factors effect patients' contentment (Mani $\square$ sa Merkezefendi State Hospital as a Sample). MSc Thesis, Beykent University, Istanbul, Turkey.

Atilla, G., 2012. The relation between emotional intelligence and patient satisfaction in hospitals: Isparta province example. Doctoral Dissertation, Suleyman Demirel University, Isparta, Turkey.

Boulding, W., S.W. Glickman, M.P. Manary, K.A. Schulman and R. Staelin, 2011. Relationship between patient satisfaction with inpatient care and hospital readmission within 30 days. The Am. J. Manage. Care, 17: 41-48.

Butler, D., S.L. Oswald and D.E. Turner, 1996. The effects of demographics on determinants of perceived health-care service quality. The case of users and observers. J. Manage. Med., 10: 8-20. DOI:10.1108/02689239610146508

Diamantopoulos, A. and J. Siguaw, 2000. Introducing LISREL: A Guide for the Uninitiated. 1st Edn., Athenaeum Press, Cambridge, MA., ISBN-10: 144622659X, pp: 192.

Entwistle, V.A. and O. Quick, 2006. Trust in the context of patient safety problems. J. Health Organi. Manage., 20: 397-416. DOI: 10.1108/14777260610701786

Findik, U.Y., S. Unsar and N. Sut, 2010. Patient satisfaction with nursing care and its relationship with patient characteristics. Nurs. Health Sci., 12: 162-169. DOI: 10.1111/j.1442-2018. 2009. 00511.x

Fitzpatrick, R., 1991. Surveys of patients' satisfaction: IImportant general considerations. BMJ, 302: 887-889. DOI: $10.1136 / \mathrm{bmj} .302 .6781 .887$

Gordon, T. and W. Edwards, 1997. Making the Patient Your Partner: Communication Skills for Doctors and Other Caregivers. 1st Edn., ABC-CLIO Inc., Westport, CT, ISBN-10: 0865692734, pp: 238.

Grol, R. and M. Wensing, 2000. Patients evaluate general/family practice: The EUROPEP Instrument.

Harper, P.R. and H.M. Gamlin, 2003. Reduced outpatient waiting times with improved appointment scheduling: A simulation modelling approach. OR Spectrum.

Ho, F.N., K.A. O'Donnell and Y.J. Chen, 1998. Switching HMO providers. Dissatisfaction with emergency access cited as the primary reason for disenrollment. Market. Health Serv., 18: 23-27.

Ipek, P., 2010. An application on the importance and role of the quality and patient satisfaction in healthcare services. Doctoral Dissertation, Selcuk University, Konya, Turkey.

Isik, B. and O. Tulunoglu, 2007. The evaluation of the effectiveness of quality circles method on the establishment of sedation departments in Paediatric dentistry clinic. Acta. Odontol. Turcica, 24: 31-36. 
Kangas, S., C.C. Kee and R. McKee-Waddle, 1999. Organizational factors, nurses' job satisfaction and patient satisfaction with nursing care. JONA: J. Nurs. Adm., 29: 32-42. DOI: $10.1097 / 00005110-199901000-00006$

Karaalp, T., 2014. Effects of physical environment on patient satisfaction and job satisfaction in the delivery of health services. Doctoral Dissertation, Gulhane Military Medicine Academy, Ankara, Turkey

Kee, J.W.Y., H.S. Khoo, I. Lim and M.Y.H. Koh, 2018. Communication skills in patient-doctor interactions: Learning from patient complaints. Health Pro. Edu., 4: 97-106. DOI: 10.1016/j.hpe.2017. 03.006

Khanna, S., D. Sier, J. Boyle and K. Zeitz, 2016. Discharge timeliness and its impact on hospital crowding and emergency department flow performance. Emerg. Med. Australasia, 28: 164-170. DOI: $10.1111 / 1742-6723.12543$

Kırmızı, H., 2010. General and Technical Communication. 1st Edn., Dilara Publications, Trabzon, Turkey.

Kuzhan, H., 2009. Measurement of service quality in a health care organization and factors affecting customer satisfaction. MSc Thesis, Dokuz Eylul University, Izmir, Turkey.

Meterko, M., D.C. Mohr and G.J. Young, 2004. Teamwork culture and patient satisfaction in hospitals. Med. Care, 42: 492-498.

DOI: 10.1097/01.mlr.0000124389. 58422.b2

Okursoy, A., 2010. Health system of Turkey and evaluation of public hospitals performance. Doctoral Dissertation, Adnan Menderes University, Aydin, Turkey.

O'Leary, K.J., D.M. Liebovitz and D.W. Baker, 2006. How hospitalists spend their time: insights on efficiency and safety. J. Hospital Med., 1: 88-93.

DOI: $10.1002 / \mathrm{jhm} .88$

Raosoft, 2004. Sample size calculator. Raosoft. http://www.raosoft.com/samplesize.html

Rhodes, P., S. Campbell and C. Sanders, 2016. Trust, temporality and systems: how do patients understand patient safety in primary care? A qualitative study. Health Exp., 19: 253-263. DOI: 10.1111/ hex.12342

Roter, D.L., M. Stewart, S. Putnam, M.J. Lipkin and W. Stiles et al., 1997. Communication patterns of primary care physicians. JAMA. DOI:10.1001/jama.277.4.350
Schermelleh-Engel, K., H. Moosbrugger and H. Müller, 2003. Evaluating the fit of structural equation models: tests of significance and descriptive goodness-of-fit measures. Meth. Psychol. Res. Online, 8: 23-74.

Silvestro, R., 2005. Applying gap analysis in the health service to inform the service improvement agenda. Int. J. Quality Reliability Manage., 22: 215-233. DOI: $10.1108 / 02656710510582462$

Stewart, M., J.B. Brown, H. Boon, J. Galajda and L. Meredith et al., 1999. Evidence on patient-doctor communication. Cancer Prev. Control, 3: 25-30. DOI: 10.1016/S0749-0690(05)70005-7

Tang, P.C. and C. Newcomb, 1998. Informing patients: a guide for providing patient health information. J. Am. Med. Inform. Assoc., 5: 563-570. DOI: 10.1136/jamia. 1998.0050563

Tucker, J.L., 2002. The moderators of patient satisfaction. J. Manage. Med., 16: 48-66. DOI: $10.1108 / 02689230210428625$

Tüfekçi, N. and H. Asığbulmuş, 2016. The factors that effective in the choice of hospital and patient satisfaction: the sample of Isparta. J. Current Res. Health Sector, 6: 71-92.

Turner, P.D. and L.G. Pol, 1995. Beyond patient satisfaction. Broaden the scope of quality measurement by integrating the marketing view with other perspectives. J. Health Care Market., 15: 45-53. PMID: 10152794

Vahey, D.C., L.H. Aiken, D.M. Sloane, S.P. Clarke and D. Vargas, 2004. Nurse burnout and patient satisfaction. Med. Care, 42: II-57-II-66. DOI: 10.1097/01.mlr.0000109126.50398.5a

Weiss, E.N., 1990. Models for determining estimated start times and case orderings in hospital operating rooms. IIE Trans., 22: 143-150. DOI: $10.1080 / 07408179008964166$

Williams, B., 1994. Patient satisfaction: a valid concept? Soc. Sci. Med., 38: 509-516. DOI: $10.1016 / 0277-9536(94) 90247-\mathrm{x}$

Worthington, D.J., 1987. Queueing models for hospital waiting lists. J. Operat. Res. Soc., 38: 413-422. DOI: $10.1057 /$ jors. 1987.69 